\title{
Accounting Information Systems
}

\author{
Dr. Tawfiq Abu-Raqabeh \\ North American University, USA
}

Received: October 9, 2018

Accepted: December 8, 2018 Published: December 11, 2018

doi:10.5296/elr.v4i2.14045

URL: https://doi.org/10.5296/elr.v4i2.14045

\begin{abstract}
Today's swiftly changing technology, globalization, and integration of corporations has created a need for the introduction of IAS to higher education institutes. This study explores and examines the introduction of IAS to the higher education institutes. The readiness of the institutes, the problems they face to incorporate the IAS to the curriculum. The criteria utilized by ABET focuses on content and delivery of curriculum within the IS discipline. The advantages of incorporating the IAS in the curriculum for students and faculty.
\end{abstract}

Keywords: TMA

\section{Introduction}

The Accounting Information System (AIS) courses were added to traditional accounting curriculum to meet the growing demand for accountants with information system knowledge. Initially accounting departments, due to their lack of information system knowledge and faculty, had accounting students take AIS courses within the Management Information Systems (MIS) department taught by MIS faculty. The primary AIS content areas that were mentioned by accounting recruiters was system analysis and electronic data processing (EDP) (Fordham, 2005). Accounting personnel normally took four to six classes.

However, the MIS department geared their courses towards students majoring and minoring in Information Systems (IS). As such, these courses tended to be technical in nature. The demand for AIS and MIS graduates increased placing pressures on colleges and universities to produce more AIS and MIS graduates. Some schools were able to devote separate resources and move AIS courses from the MIS department to the accounting department. This allowed the accounting department to develop their own AIS curriculum. However, most accounting programs do not have a separate AIS curriculum and depended upon the MIS department to train accounting students in IS (Bryant, 1999). Since many accounting programs utilize the MIS department for AIS courses, this paper examines the accreditation process and curriculum development of MIS programs.

\section{Literature Review}

According to MacKenzie (1964) accreditation exists to develop and promote academic 


\section{Al Macrothink}

Education and Linguistics Research

ISSN 2377-1356

2018, Vol. 4, No. 2

standards. The Accreditation Board for Engineering and Technology (ABET) through the Computer Science Accreditation Board (CSAB) accredits programs in information systems. The CSAB is responsible for accrediting programs in information systems, information technology, computer sciences, and software engineering. ABET serves the public through promotion and advancement of education in applied science, computing, engineering, and technology and by promoting quality and innovation in education, by consulting and assisting in the development and advancement of education. (Challa, Kasper, \& Redmond, 2005) The criteria utilized by ABET focuses on content and delivery of curriculum within the IS discipline. There are eight criteria that ABET utilizes in accrediting MIS programs. These criteria are objectives and assessments, students, faculty, curriculum, technology structure, institutional support and financial resources, program delivery, and institutional facilities.

The objectives and assessment criteria relate that the program objectives are consistent with the institution objectives. And that the program has procedures to periodically assess itself and make necessary changes due to the assessment. The student criterion relates that students have sufficient time to complete the program. The faculty criterion relates that faculty has the requisite technology to teach the program. The curriculum relates that the program has a curriculum that combines professional course requirements with general education requirements that prepare students for a career in the IS environment. Since students are acquiring new skills in technology, the technology criterion relates that there are adequate computer resources to support the program. The institutional support and financial resources criterion relates that there is sufficient support from the institution as well as financial resources to support eh program in meeting its objectives. The program delivery criterion relates that there is sufficient faculty in the right technical mix that allows the teaching and scholarly activity to occur to support the program. The institutional facilities criterion relates to the facilities that are on the institution (library, electronic information retrieval systems, classrooms, offices, and other facilities) that support the program.

The skills and knowledge that are taught to IS students include:

- familiarity with main frame computing

- client-server computing

- database management

- wireless communication

- system analysis and design

- computer programming and query language

- $\quad$ encryption facilities

- information assurance

- systems life development cycle

The skill set reflects highly technical skills associated with computer science. According to a case study conducted by Fordham (2005) at a mid-sized university, many AIS alumni want to include MIS technical computing courses as part of an AIS curriculum. The reason is that the MIS courses teach reasoning concepts not taught in accounting courses. Many AIS alumni stated that the methodology taught for thinking and reasoning in MIS courses changed the 
way they approached and analyzed problems.

For example, AIS alumni stated that the programming courses taught reasoning concepts such as "conditional and unconditional branching, process flow, sequence and return, comparisons, structured design, variable definitions, and related computer ideas." The AIS alumni stated that the programming courses gave them the skills necessary to communicate with technical personnel. In addition, AIS alumni stated that computer programming courses provided a model of relation ships between real-world subjects and related information (Fordham, 2005). The AIS alumni felt that the technical MIS courses assisted them in converting observable measurements from business processes into structured information - information that could be used in problem solving (Fordham, 2005).

Alavi (1994) stated that there are three attributes that can be associated with effective learning. They are: "a) active learning and construction of knowledge, b) cooperation and teamwork in learning, and c) learning via problem-solving." Ives and Jarvenpaa (1996) notes "where once schools provided a discrete career spanning set of concepts and tools, now they will build the skills and motivation for lifelong learning." A key item in this area and utilize in IS education technology mediated learning (TML). According to Alavi and Leidner (2001), TML is defined as "an environment in which the learner's interactions with learned materials (readings, assignments, exercises, etc.) peers, andlor instructors are mediated through information technology." (Hardway \& Scamell, 2005).

The use of TML encourages students to be more responsible for their learning. Increasingly employees are expecting employees to be self-sufficient in the workplace. This entails employees to take responsibility for their learning. As such, TML forces students to become more responsible for learning new material and applying new skills in problem-solving situations. This prepares students as to what to expect in the workplace. Hardaway and Scamell (2005) have noted several studies in which there was no statistical difference between students learning on a classroom environment and students learning in a TML environment. Yet, Wilkes, Simon, and Brooks (2006) conducted a study involving 178 students at a large urban university concerning the differences between an online course and an on-campus course. The survey contained 27 questions and there was an equal representation of males and female students. The survey revealed that $19 \%$ of all students would not take an online course, with the percentage of females almost twice as the percentage of males who would not take an online course. However, almost $53 \%$ of all students stated that they would like to take an online class, with an $8 \%$ increase of males to females. A similar survey was given to faculty concerning their desirability of teaching an online class. There were 3 times as many males as female faculty. Almost $30 \%$ of the faculty stated that they would not teach an online course, with a $7 \%$ increase of males to females. However, almost $56 \%$ of all faculty stated that they would teach an online course, with almost a $17 \%$ increase of females to males. Thus, there were higher negative attitudes by the faculty in teaching online classes as compared to the higher positive feeling by students in taking online classes. This dichotomy may hamper future efforts to move MIS course to an online platform.

One of the main roles of IS people is to develop and maintain information systems (Avison, Cole, \& Fitzgerald, 2006) One of the main courses that is taught in IS programs and reviewed 


\section{Macrothink}

by ABET are systems development life cycle (SDLC) courses. According to Avison, Cole and Fitzgerald (2006) information systems development is "at the meeting place of the three basis of the IS discipline: information system and communication (ICAT), organization, and human dimension". In addition, the IS requires an understanding of what lies behind the techniques and methodologies. The breath of knowledge needed in IS development allows students to see where other topics fit in.

According to Fowler (2002), development methodologies in SDLC are important because they "impose a disciplined process upon software development more predictable and more efficient". Students are expected to stimulate or execute system development activities in a comprehensive project. The application of the concept is to enable students to gain an appreciation of what is involved in SDLC.

As the field of IS has changed so has SDLC. SDLC in the 1960'ss and 1970's was limited to large batch transaction processing on main frame computers, in many cases with large organizations. However, the computing environment has changed with client-server networks, wireless networks, structured query language (SQL), different software operating systems, Microsoft Windows administration, and different software programming languages.

According to Royce (1970), the sequences of phases to guide SDLC are:

- systems requirements determination

- software requirement determination

- analysis

- program design

- coding

- testing

- operations

These activities are divided so a project can more forward in a linear fashion. While these SDLC phases were developed in the 1970's, they are being taught in IS programs and implemented in the workplace today. The reason for very little change is that the SDLC process is a rigorous methodical approach to project completion and implementation. Yet in the 1990's there were several concepts added to the SDLC curriculum. These concepts are interactive interfaces, client-server systems, enterprise systems, and web-based technologies.

However, there has been discussions in the IS community to modify the SDLC course. These discussions have centered on revisions to the SDLC course in terms of redefining the methodologies, techniques, models, and tools needed to be taught. Three major revisions have been mentioned in the IS community. They are incorporating object-oriented techniques, the emergence of the iteration approach, and the increasing adoption of the agile approach.

The object-oriented technique combines data and specific procedures that operate on the data into an "object". The object combines data and program code. The objects are defined, programmed, documented, and saved for use with future application. Because objects can be reusable, it can take less time and expense in writing new software code.

The iterative approach is building a preliminary design, trying it out, refining it, trying it again, etc. The steps are repeated until the desired result is achieved. An advantage of this 
technique is to see changes as they occur and based upon the result of the change, a firm can redirect resources to improve upon the systems development.

The third revision is to take a less structured approach in SDLC development to a more agile approach. According to Batra and Satzinger (2006), the agile approach would have developers value individuals and interactions over process and tools (tool is software support for a technique; a technique is a how a model is used), working software over comprehensive documentation, customer collaboration over contract negotiations, and responding to change over following a plan. Batra and Satzinger (2006) state "agile approach focuses on developing working (software) code built through short iterations and relies on feedback rather than planning as a guiding mechanism."

The original structured SDLC curriculum plus the changes that occurred in the 1990's plus the recent recommendations entail the movement from a single SDLC semester course to a two semester SDLC course.

A major trend in business is e-commerce and there are discussions within the IS community as to adding an e-commerce course to the AIS/MIS curriculum. The emergence of e-commerce has modified many business processes and introduced corresponding changes into business information systems. (Moshkovich, Merhitov, \& Olson, 2006) However, there are challenges as accreditation standards establish certain requirements for a business core. Also, there are a minimum number of hours needed for a degree (120 hours for an undergraduate degree). Therefore, students may not be motivated to take additional courses above the minimum number needed to acquire a degree.

E-commerce knowledge and skills are summed up as "web development skills". The student needs a working knowledge of programming language and web development skills. According to a study performed by Moshkovich, Merhitov, and Olson (2006), e-commerce skills are divided into four groups which are: e-commerce concepts, client-side web development skills, telecommunications, and fundamentals of information systems. Moshkovich, Merhitov, and Olson (2006) also determined that students need to have more knowledge in client-side web development and general support tools than in the areas of ser-side web development.

In addition, in a study conducted by Williams and Pomykalski (2004) of 134 accredited schools, e-commerce courses were present in $23 \%$ of the schools. The study also noted that $28 \%$ of the schools had a course in emerging technologies, which could encompass some of the concepts of e-commerce.

One of the difficulties that schools have in teaching MIS courses is having the students comprehend and retain the technical knowledge gained in MIS classes. Sheu and Wong (2006) referenced several studies which state that learning becomes active when students acquire new experiences using existing knowledge and experience. Also, they noted that students learn more if the learning is active and not passive and group activities encourages inductive learning. Sheu and Wong (2006) developed a learning tool called Knowledge Assimilation Schems (KAS). KAS is a web based learning tool consisting of two components: a knowledge representation framework for describing relationships among knowledge entities and a knowledge discovering process for assimilating external knowledge. 


\section{Ml Macrothink}

They utilize a three stage process: a0 guide the students to organize their knowledge onto a familiar framework, b) develop an analogous framework structure to model new knowledge concepts, and c) assimilate both existing and incoming concepts through aggregation and generalization. Sheu and Wong have conducted questionnaires with 90 participants with $80 \%$ of the participants agree that KAS engages active learning and $68 \%$ of the participants agree that KAS facilitates concept establishment.

\section{Conclusions}

According to Lightfoot (1999) "the right balance between fundamental knowledge of the IS field and technical study necessary to obtain an entry job in the marketplace is one of the major challenges of the undergraduate curricular design for an MIS major." In addition, undergraduate MIS education should provide students with knowledge and skills in current technologies (Moshkovich, Merhitov, \& Olson, 2006).

The challenge among educators is strike the right balance between what needs to be taught, how it should be taught, and is assisting students in the workplace. The IS workplace is becoming field is becoming more diverse and technical which places greater emphasis on AIS majors to learn more technical material. This also has an impact on the availability of courses and the correct mix of course. As noted earlier, only $23 \%$ of the accredited schools offered an e-commerce course. Yet more businesses are utilizing e-commerce which would entail a change to the MIS curriculum. One way of relieving the availability of classes is to offer more courses online. However, there is a dichotomy between faculty and students in terms of online learning.

There are significant challenges ahead in AIS/MIS curriculum and it remains to be seen whether the educational community can overcome these challenges.

\section{References}

Accreditation Board for Engineering and technology (ABET) www.abet.org.

Avison, D., \& Cole, M. (2006). Reflections on Teaching Information Systems Analysis and Design: From Then to Now! Journal of Information Systems Education, 17(3), 253-256.

Bataveljic, P., Eastwoord, M., \& Seefried, H. (2006). An Approach to Teaching ObjectOriented Analysis and Design. Journal of Information Systems Education, 17(3), 267-272.

Batra, D., \& Satzinger, J. (2006). Contemporary Approaches and Techniques for the Systems Analyst. Journal of Information Systems Education, 17(3), 257-265.

Challa, C., Kasper, G., \& Redmond, R. (2005). The Accreditation Process for IS Programs in Business Schools. Journal of Information Systems Education, 16(2), 207-216.

Chilton, M., McHaney, R., \& Chae, B. (2006). Data Modeling Education: The Changing Technology. Journal of Information Systems Education, 17(1), 17-20.

Fordham, D. (2005). New Roles for AIS Courses: A Surprising Finding from a Case Study. Journal of Information Systems, 19(1), 113-129. https://doi.org/10.2308/jis.2005.19.1.113

Hardaway, D., \& Scamell, R. (2005). Use of Technology-Mediated Learning Instructional Approach for Teaching and Introduction to Information Technology Course. Journal of Information Systems Education, 16(2), 137-145.

Harris, A., Lang, M., Oates, B. \& Siau, K. (2006). Systems Analysis \& Design: An Essential 


\section{Macrothink

Part of IS Education. Journal of Information Systems Education, 17(3), 241-248.

Lamberton, B., Fedorowicz, J., \& Roohani, S. (2005). Tolerance for Ambiguity and IT Competency among Accountants. Journal of Information Systems, 19(1), 75-95. https://doi.org/10.2308/jis.2005.19.1.75

Laudon, K., \& Laudon, J. (1996). Management Information Systems: Organization and Technology. Upper Saddle: Prentice-Hall.

Lightfoot, J. M. (1999). Fads versus Fundamentals: The Dilemma for Information Systems Curricular Design. Journal of Education for Business, 75(1), 43-51. https://doi.org/10.108 0/08832329909598989

McRobb, S. (2006). Challenging Students: Reflections on the Development and Delivery of an Undergraduate Module that Introduces the Full Systems Development Life Cycle. (Fall 2006). Journal of Information Systems Education, 17(3), 303-313.

Moshkovich, H., Mechitov, A., \& Olson, D. (2006). E-Commerce and the Undergraduate MIS Curricula: An Exploratory Study. Journal of Information Systems Education, 17(2) 185-194.

Rose, E., Heron, J., \& Sofat, I. (2005). Student Understanding of Information Systems Design, Learning and Teaching: A Phenomenography Approach. Journal of Information Systems Education, 16(1), 183-195.

Sheu, M., \& Wong, W. (2006). A Knowledge Assimilation Schema for Acquiring Technical Knowledge. Journal of Information Systems Education, 17(2) 223-229.

Tetard, F., \& Patokorpi, E. (2005). A Constructivist Approach to Information Systems Teaching: A Case Study on a Design Course for Advanced Level University Students. Journal of Information Systems Education, 16(2), 167-229.

Van Vliet, P., \& Pietron, L. (2006). Information Systems Development Education in the Real World - A Project Methodology and Assessment. Journal of Information Systems Education, 17(3), 285-293.

Wilkes, R., Simon, J., \& Brooks, L. (2006). A Comparison of Faculty and Undergraduate Students' Perceptions of Online Courses and Degree Programs. Journal of Information Systems Education, 17(2), 131-140.

\section{Copyright Disclaimer}

Copyright reserved by the author(s).

This article is an open-access article distributed under the terms and conditions of the Creative Commons Attribution license (http://creativecommons.org/licenses/by/3.0/). 